\title{
PELOS CAMINHOS DAS PEDRAS: OS DESAFIOS DAS COOPERATIVAS NA MINERAÇÃO EM PEQUENA ESCALA \\ THE STONE WAYS: THE CHALLENGES IN COOPERATIVES IN SMALL- SCALE MINING
}

\author{
Alex dos Santos Macedo ${ }^{I}$ \\ Alan Ferreira de Freitas ${ }^{2}$ \\ Alair Ferreira de Freitas ${ }^{3}$ \\ Maria de Lourdes Souza Oliveira ${ }^{4}$
}

\section{Resumo}

$\mathrm{O}$ artigo procurou refletir se o ambiente institucional que envolve as cooperativas na Mineração Pequena Escala (MPE) favorece a efetividade desta forma organizacional no âmago desta atividade econômica. Sendo assim, o estudo buscou compreender o processo de formalização de cooperativas minerais no ambiente institucional da MPE, para, em seguida, apontar os constrangimentos à formalização e os desafios enfrentados na operacionalização da atividade mineral por essas organizações. $\mathrm{O}$ estudo foi caracterizado como exploratório-descritivo, de abordagem qualitativa e método de estudo de casos em duas cooperativas localizadas no Estado de Minas Gerais. Foram realizadas 25 entrevistas com dirigentes e associados das cooperativas, representantes do poder público local, do cooperativismo em Minas Gerais e do órgão mineral em âmbito estadual e federal. Os resultados indicam processos distintos de constituição das cooperativas. Enquanto em uma, os garimpeiros se organizaram para se antecipar ao processo de fiscalização estatal, em outra, os pequenos mineradores se constituíram a partir da imposição do Estado. Ademais, os resultados indicam que o processo de formalização e operacionalização da atividade mineral é complexo em função do hiato existente entre aquilo prevê o ambiente institucional da MPE de prioridade e fomento às cooperativas do ramo mineral e a realidade dessas organizações. Nesse sentido, elas enfrentam desafios para acessar o direito mineral e ambiental, as políticas públicas, crédito, assessoria, treinamento, tecnologia, suporte organizacional, entre

1 Doutor em Administração pela Universidade Federal de Viçosa (UFV), Viçosa - MG, Brasil. E-mail: alexmacedo. ufv@gmail.com

2 Doutor em Extensão Rural (UFV). Professor Adjunto do Departamento de Administração e Contabilidade (UFV). E-mail: freitasalan@yahoo.com.br

3 Doutor em Administração pela Universidade Federal de Minas Gerais (UFMG). Professor do Departamento de Economia Rural da UFV. E-mail: alair.freitas@ufv.br

4 Doutora em Desenvolvimento, Agricultura e Sociedade pela Universidade Federal Rural do Rio de Janeiro (UFRRJ). Professora aposentada da Universidade Federal de Lavras (UFLA) tendo atuado no Departamento de Administração e Economia. E-mail: marocabj@gmail.com 
outros. Esses problemas do ambiente institucional afetam a capacidade de gestão mineral e ambiental realizados por essas organizações, compromete o desenvolvimento econômico e social dos associados dessas cooperativas, bem como dificulta a possibilidade de contribuírem para o desenvolvimento local.

Palavras-chave: Arranjo Institucional. Mineração em Pequena Escala. Cooperativa Mineral. Formalização de Cooperativas.

\section{Abstract}

the article sought to reflect on whether the institutional environment involving cooperatives in Mining Small Scale (MPE) favors the effectiveness of this organizational form at the heart of this economic activity. Thus, the article sought to understand the process of formalization of mineral cooperatives in the institutional environment of SSM, to then point out the constraints to formalization and the challenges faced in the operationalization of mineral activity by these organizations. The study was characterized as exploratory-descriptive, qualitative approach and case study method in two mineral cooperatives located in the State of Minas Gerais. Twenty-five interviews were conducted with leaders and members of cooperatives, representatives of local public authorities, cooperatives in Minas Gerais, and state and federal agencies. The results indicate different processes of incorporation of cooperatives. While in one, the prospector organized themselves to anticipate the process of state control, in another, the small miners, they were constituted from the imposition of the State. In addition, the results indicate that the process of formalization and operationalization of the mineral activity is complex due to the gap existing between what predicts the institutional environment of the MPE of priority and foment to the cooperatives of the mineral branch and the reality of these organizations. In this sense, they face challenges to access mineral and environmental law, public policies, credit, advice, training, technology, organizational support, among others. These problems of the institutional environment affect the capacity of mineral and environmental management carried out by these organizations, it jeopardizes the economic and social development of the members of these cooperatives, as well as hinders the possibility of contributing to local development.

Keywords: Institutional Arrangement. Small Scale Mining. Mineral Cooperative. Formalization of Cooperatives.

\section{INTRODUÇÃO}

A atividade de mineração em pequena escala (MPE) é realizada pelas pequenas empresas de mineração e pela mineração artesanal, o garimpo. Segundo o Banco Mundial, mais de 80 países contam com a MPE em seus territórios, que envolve cerca de 100 milhões de pessoas. (THE WORLD BANK, 2013). Em suma, a MPE é adotada para descrever aquela atividade que é realizada de forma individual, em grupos, famílias ou cooperativas e em muitos casos atuando na informalidade, com nenhum ou pouquíssimo aporte tecnológico. Em alguns países, a MPE é tão importante quanto à mineração em grande escala devido ao volume de trabalho e renda gerados. (HENTSCHEL et al, 2002).

Apesar da sua relevância, a atividade de MPE, quando denominada de garimpo, é caracterizada tanto pelos órgãos governamentais, quanto pela sociedade, como uma atividade realizada de forma ilegal e precária, de grande ônus ambiental e social. Discutindo os desafios da MPE na África do Sul, Ledwaba (2017) os organizou em cinco grandes frentes de trabalho: acesso ao direito mineral, capital, mercados, tecnologia e conhecimentos, além de suporte institucional. 
Corroborando os argumentos de Ledwaba (2017), Fold, Jonsson \& Yankson (2014) endossam que o debate sobre a pequena mineração, além de envolver aspectos da formalização precisa também se ater a melhoria das condições de trabalho, propiciando ganhos para os mineradores e para o meio ambiente. Somam-se a isso os riscos ocupacionais, degradação ambiental, acesso restrito às linhas de crédito, tecnologia apropriada e apoio institucional.

Outro desafio apontado por Fold, Jonsson \& Yankson (2014) envolve o acesso à área de extração mineral pelos pequenos mineradores que encontram diversas dificuldades para o acesso ao direito mineral em função da ausência ou insuficiente conhecimento sobre o marco legal e as necessárias pesquisas geológicas, escassez de recursos financeiros e custas dos processos, com as taxas e questões burocráticas. Ademais, a capacidade limitada dos órgãos minerais em informar os procedimentos aos pequenos mineradores para obtenção dos registros, dificultam o acesso, bem como, favorecem as grandes empresas do setor ou especuladores, que contam com condições e conhecimento para obtenção do direito mineral. (FOLD; JONSSON; YANKSON, 2014).

Não obstante, no contexto latino-americano, países, como o Brasil, não estão sendo eficientes no controle, regulação ou proibição das atividades minerais ilegais. Na Colômbia, por exemplo, o Código Mineral não faz diferenciação entre grandes e pequenos mineradores, o que contribuí para deixar em desvantagem os garimpeiros e pequenos mineradores na obtenção pelo direito mineral. Além do mais, o custo do processo, agravado pelo baixo nível de organização dos garimpeiros, ausência de recursos financeiros e pouco acesso às linhas de financiamento pelos mineradores informais contribui para dificultar a formalização dessa atividade econômica. Soma-se a isso, uma longa tradição de trabalho informal que torna pouco atraente o processo de formalização. (ECHAVARRIA, 2014).

Cabe endossar, em especial, que o trabalho do garimpeiro se forjou ao longo dos anos de forma individual, nômade, ora explorando em um determinado local ora em outra região, fazendo a sua própria comercialização e seus contratos de trabalho. (BITENCOURT, 2009). Assim, formalizar a atividade implica atuar em conformidade com os normativos do direito mineral, ambiental e trabalhista. Por outro lado, a formalização pode ajudar os empreendimentos da MPE a acessar direitos, políticas públicas, mercados, crédito, entre outros. (SIEGEL; VEIGA, 2009).

Frente a este contexto adverso do setor mineral, o Estado brasileiro e muitos países da América Latina e Caribe a partir dos anos 90 passaram a incentivar o associativismo e o cooperativismo entre os mineradores e garimpeiros informais na MPE como forma de fomentar a organização social. A regularização e a aprovação das lavras passaram a priorizar as cooperativas, como meio de garantir a formalização. (BARRETO, 2003).

Na perspectiva do Estado brasileiro, o cooperativismo pode representar uma forma alternativa de organização das atividades informais da mineração, bem como o acesso ao direito mineral, a cidadania, ao crédito, a políticas públicas, a programas de capacitação e a comercialização de sua produção. (BRASIL, 2008).

Para tanto, em 1988, por meio da Constituição Federal (BRASIL, 1988), o Estado brasileiro concedeu prioridade de organização aos garimpeiros que estivessem explorando uma determinada região a se organizarem em cooperativas, inclusive incentivando e favorecendo a organização destes trabalhadores, por meio de programas ou políticas públicas. Isso, de certa forma, favoreceu a constituição de mais um ramo do cooperativismo pela Organização das Cooperativas Brasileira (OCB), o ramo mineral. (FREITAS; FREITAS; MACEDO, 2016). As cooperativas do ramo mineral são organizações constituídas por variados atores (garimpeiros, donos de dragas, de balsas etc.) do segmento mineral para viabilizar a extração, a industrialização e a comercialização dos produtores minerais.

Entretanto, há um hiato entre a garantia constitucional de prioridade e fomento às cooperativas do ramo mineral e a realidade vivenciada pelas organizações do setor. O que de certa forma, contribui 
para dificultar a organização desses empreendimentos. Não só isso, esse cenário contribui para que cooperativas sejam criadas apenas como 'fachadas' para se trabalhar de acordo com a lei. (BARRETO, 2008; BITENCOURT; AMODEO, 2008; BITENCOURT, 2009). Entende-se como cooperativas de fachadas aquelas organizações constituídas com intuito de dar uma aparência legal ao cumprir os requisitos burocráticos exigidos para tal, mas que na sua essência não apresentam práticas de cooperação, de participação, de gestão democrática e de autogestão, valores do cooperativismo.

Desta forma, cabe endossar que formalizar a atividade MPE por meio de cooperativas não significa necessariamente promover a organização social, tão pouco garantir a base de superação dos desafios organizacionais enfrentados pelos pequenos mineradores. Em relação ao número de cooperativas, segundo dados do Departamento Nacional de Produção Mineral (DNPM), em 2014 eram 185, concentradas em sua maioria nas regiões Norte (37\%) e Nordeste (18\%) do país. Dados de 2019, apontam o registro na Organização das Cooperativas Brasileiras (OCB) de 95 cooperativas, que congregam 59 mil associados a estas organizações, gerando 177empregos diretos. (OCB, 2019).

Portanto, cabe refletir se o ambiente institucional que envolve as cooperativas na MPE favorece a efetividade desta forma organizacional no âmago desta atividade econômica. Sendo assim, o artigo procurou compreender o processo de formalização de cooperativas na MPE à luz de aspectos normativos, analisando a relação entre a organização cooperativa, o processo organizativo e o ambiente institucional que condiciona a ação na MPE, para apontar os constrangimentos a formalização e os desafios enfrentados na operacionalização da atividade mineral.

Para tanto, além da análise do ambiente institucional procedeu-se a um resgate histórico da trajetória de formação de duas cooperativas em Minas Gerais, a Uniquartz, na cidade de Corinto, e a Microminas, em Córrego Fundo. Essas cooperativas foram constituídas para que houvesse, por parte do grupo de mineradores, o acesso ao direito mineral para poderem operar as jazidas.

Este artigo está organizado em quatro seções, além desta introdução. No primeiro momento, discorreu-se sobre o ambiente institucional da MPE no Brasil. Após as reflexões desta questão, delineouse os caminhos metodológicos. E para apresentação e discussão dos resultados, discutiu-se o processo de formação e os entraves a formalização das cooperativas em seu contexto local para, em seguida, tecer as considerações finais.

\section{O AMBIENTE INSTITUCUIONAL DA MINERAÇÃO EM PEQUENA ESCALA - MPE}

Segundo Barreto (2001), a MPE divide-se em pequena empresa de mineração e a mineração artesanal, o garimpo. A mineração artesanal seria aquela realizada de forma individual ou em pequenos grupos, podendo ter laços de parentesco ou não e sem empregar mão de obra contratada. O local de trabalho pode ser próprio, de terceiros ou área pública, entretanto, não possuem em sua maioria, licença ou permissão formal, caracterizando, assim, como trabalhadores sem controle estatal, atuando de forma ilegal. (CHAKRAVORTY, 2001).

No Brasil, o termo garimpeiro origina-se de "grimpa - garimpeiro - a indicar os homens que escondiam no recôndito das serras para retirar clandestinamente o ouro e diamantes das lavras cedidas aos senhores e impedidas ao trabalho avulso." (SALOMÃO, 1984, p. 42). Desta forma, observa-se que a palavra garimpeiro já carrega consigo uma noção de atividade ilegal, marginal e de repressão da força de trabalho. (COSTA, 2007). No código mineral vigente desde 1967, aprovado ainda no regime militar, a atividade de garimpo em seu artigo 72 é caracterizada pela forma rudimentar de minerar, pela natureza dos depósitos explorados e pelo trabalho de caráter individual, sempre por conta própria. (BRASIL, 1967).

Já a pequena empresa de mineração, de uma forma mais ampla, caracteriza-se por ser mais 
mecanizada que a mineração artesanal. Em relação ao título do direito mineral, ou seja, a autorização ou concessão estatal para exploração da atividade mineral, a MPE pode ou não ter o direito de exploração. Desta forma, as principais características da MPE envolvem a exploração de jazidas marginais ou pequenas, falta de capital, trabalho intensivo e com baixa taxa de recuperação, dificuldade de acesso aos mercados e serviços de apoio institucional, além de baixos padrões de segurança e saúde no trabalho, bem como alto impacto sobre o meio ambiente. (IIED; WBCSD, 2002).

Para tentar favorecer os pequenos mineradores, em especial os garimpeiros, o Estado brasileiro incentivou por meio da Constituição Federal de 1988 a formação de cooperativas, estabelecendo que estas teriam prioridade tanto na autorização quanto na concessão para pesquisa e lavra dos recursos e das jazidas daqueles minerais considerados garimpáveis. (BARRETO, 2001).

Já em 1989, por meio da Lei 7.805, instituiu-se o Regime de Permissão da Lavra Garimpeira. Segundo Barreto (2001, p. 147), esse ordenamento jurídico é "o pilar da legislação ordinária para a atividade garimpeira". Seu intuito foi o de facilitar o acesso dos garimpeiros ao direito mineral, não exigindo trabalhos prévios de pesquisa como nos demais regimes que são concedidos para as demais empresas do setor, todavia há a necessidade de trabalhos prévios de licença ambiental. (BRASIL, 1989).

Segundo o art. $5^{\circ}$ da Lei 7.805 , a permissão será outorgada a brasileiros e a cooperativa de garimpeiros. Ainda nesse ordenamento jurídico, os trabalhos nas áreas de garimpagem devem ser realizados de preferência de forma associativa, tendo as cooperativas prioridades na permissão da lavra. Neste sentido, com a preferência às cooperativas e a extinção do regime de matrícula, os garimpeiros que quisessem continuar exercendo suas atividades deveriam procurar se organizar em formas associativas. "Embora não necessariamente os garimpeiros tenham que formar uma cooperativa para requerer a permissão de lavra, eles só terão prioridade na permissão da lavra caso estejam agrupados nesse tipo de organização." (BITTENCOURT, 2009, p. 48).

Avançando um pouco mais, em 2008, houve a promulgação do Estatuto do Garimpeiro, Lei 11.685, em que há previsão que os garimpeiros realizarão as atividades de extração das substâncias minerais em várias modalidades de trabalho, autônomo, em regime de economia familiar, individual com relação empregatícia, por meio de contrato de parceria registrado em cartório e em cooperativa e outra forma de associativismo. (BRASIL, 2008).

Segundo este normativo em seu art. 11, "fica assegurado o registro do exercício da atividade de garimpagem nas carteiras expedidas pelas cooperativas de garimpeiros." (BRASIL, 2008), ou seja, compete às cooperativas de garimpeiros a emissão da carteira ao garimpeiro para o exercício de sua atividade. Dito de outra forma, diante desta nova legislação, a comprovação de atividade de garimpeiro seria realizada mediante o ingresso em uma cooperativa, tornando, assim, associados, sócios do negócio. (BITTENCOURT, 2009).

Com esta legislação, os garimpeiros individualmente, segundo Bittencourt (2009) ficam sem um arcabouço legal que regule sua atividade enquanto trabalhadores, uma vez que, no regime de matrícula, conforme o Código de 1967, os garimpeiros possuíam uma matrícula que assegurava o direito de exploração e comercialização e, ao mesmo tempo, servia como comprovante em termos previdenciários para aposentadoria.

A permissão da lavra garimpeira não será superior a cinco anos, podendo ser sucessivamente renovada e ela não depende previamente de trabalhos de pesquisa. O título é pessoal e pode ser transferido mediante autorização do DNPM para outra pessoa que cumprir os requisitos desta legislação. A permissão também depende previamente de licenciamento ambiental concedido pelo órgão competente. (BRASIL, 1989).

Em 2018, foi publicado pela Presidência da República o Decreto ${ }^{\circ}$ 9.406, de 12 de junho de 
2018, que regulamenta o Código de Mineração de 67, bem como as Leis n ${ }^{\circ}$ 6.567/78 (dispõe sobre regime especial para exploração e o aproveitamento das substâncias minerais) e nº 7.805/89 (cria o regime de permissão de lavra garimpeira, extingue o regime de matrícula, e dá outras providências), e parte da Lei no 13.575/17, que criou a Agência Nacional de Mineração (ANM). (BRASIL, 2018).

Diante do exposto, o que se observa em relação à atividade garimpeira após a Constituição de 1988 e as demais legislações sobre esta atividade é uma descaracterização do garimpeiro enquanto trabalhador individual e inserção da forma associativa como meio para organização desses trabalhadores para a exploração mineral. (LIMA et al., 2004).

Desta forma, cabe refletir se a forma cooperativa seria adequada ao contexto do garimpo e se esta organização estaria favorecendo a cooperação como meio de organização social da produção no garimpo, uma vez que, a construção de processos culturais distintos no garimpo é pautada pela individualidade, sigilo e disputa. (BITENCOURT, 2009).

Portanto, é importante ressaltar que o ambiente institucional da atividade garimpeira é formado pelo seu aparato legal, modificado a partir da Constituição Federal de 1988, mais a tradição do garimpo e a sua cultura que influenciam diretamente os seus pressupostos comportamentais. (BITENCOURT et al. 2010).

Quanto ao aspecto cultural, ainda persiste no garimpo, um ambiente onde a cooperação, juntamente com a adoção de ações coletivas, pode figurar como algo de difícil efetivação, "geralmente os garimpeiros unem-se em oposição a outros garimpeiros que os ameaçam ou, mais frequentemente, aos donos e empresários do garimpo." (GUANÃES, 2001, p. 73).

Especialmente pelas contradições entre, por um lado, a cultura individualista e solitária que historicamente caracterizou os garimpeiros e a atividade garimpeira em geral (GUANÃES, 2001; GUIMARÃES, 1982) e, por outro lado, a cultura cooperativista, regida por pressupostos de cooperação, participação e autogestão (RIOS, 1987; SCHNEIDER, 1999; 2012), este formato organizacional encontra dificuldades de legitimação no garimpo. (FORTE, 1994; BITENCOURT; AMODEO, 2008; BITENCOURT, 2009).

A título de exemplo, Bitencourt et al. (2010, p. 408) em seu estudo expõem que a cooperativa investigada "[...] apropriou-se da forma legal cooperativa sem a necessária sensibilização do quadro social, sobre o que isso realmente significava". Ou seja, a figura cooperativa passa a existir para resolver um problema imediato, a resposta a demanda do ambiente institucional, o atendimento da legislação ambiental e mineral.

Quando há processos de fiscalização por parte do Estado e as minas são embargadas, a formalização em sociedades cooperativas é uma exigência imediata, demandada pelo Estado para que esses trabalhadores possam acessar o direito mineral e ambiental e, assim, retornar suas atividades laborais. Estudos já desenvolvidos sobre o assunto evidenciaram processos de constituição de cooperativas na mineração de cima para baixo ou mesmo criadas para acessar alguma política de incentivo, como os estudos de Forte (1994), Bitencourt (2009), Bitencourt et al. (2010) \& Macedo et al. (2016).

Todavia, é importante esclarecer que quando a organização é constituída para atender à exigência legal, não há garantias que ela funcione como mecanismo de organização social e geração de renda, mas sim como instrumento de regulação. A sua institucionalização como forma de organização econômica e social não está garantida com a simples formalização. E, os garimpeiros poderão encontrar meios de burlar as exigências normativas para continuar operando na ilegalidade e manter seus meios de produção e sustento.

Assim, defende-se que a formalização de cooperativas na mineração deve ir além da obtenção do direito mineral, visando aumentar escala, renda obtida pelos trabalhadores, em agregação de valor ao 
minério extraído. Advoga-se que a formalização das sociedades cooperativas figure como um "projeto coletivo de mudança sócio-política com uma base social de interesses convergentes.” (RIOS, 2009, p.3).

\section{CAMINHOS METODOLÓGICOS}

O estudo foi caracterizado como teórico-empírico, do tipo exploratório-descritivo, com abordagem qualitativa e método de estudo de casos (GODOY, 1995; GIL, 2007) em duas cooperativas, Uniquartz (em Corinto) e da Microminas (em Córrego Fundo), ambas localizadas em Minas Gerais.

A justificativa da escolha dessas cooperativas está relacionada ao fato delas apresentaremse legalmente constituídas, cumprindo, assim, as exigências legais para seu funcionamento; em como estarem exercendo suas atividades, ou seja, ativas, além de serem registradas no Sindicato e Organização das Cooperativas do Estado de Minas Gerais (OCEMG), requisitos necessários para acessar as políticas públicas que, por ventura, vierem a ser formuladas conforme disposição na Lei Estadual do Cooperativismo Mineiro, Lei n 15.075, de 05 de Abril de 2004. (MINAS GERAIS, 2004).

Os dados foram coletados por meio de entrevistas semiestruturadas e notas de campo, durante os meses de novembro e dezembro de 2014. Foram entrevistados os dirigentes, associados que estavam desde a fundação e associados que ingressaram posteriormente nas cooperativas. Em âmbito estadual, foram entrevistados os representantes das cooperativas minerais, da OCEMG e os responsáveis pela gestão do patrimônio mineral em Minas Gerais, o DNPM/MG e em âmbito nacional, o representante do Ministério de Minas e Energia. No total foram 25 entrevistas. Na apresentação dos resultados, os entrevistados foram organizados em grupos, conforme cargo ou situação ocupada, mantendo o seu anonimato.

Para análise dos dados procedeu-se com a análise de conteúdo, técnica apropriada para o Estudo de Caso. (GODOY, 1995). Neste trabalho, utilizamos a análise de conteúdo para a construção de categorias de análise e não para quantificá-las. Concomitantemente, utilizamos a discussão de Vergara (2006), a qual salienta que as categorias para análise podem ser definidas conforme a grade de análise escolhida: aberta, fechada e mista. Nesse estudo, adotou-se a mista, procurando intercambiar as discussões da literatura, em especial de Ledwaba (2017), Fold, Jonsson \& Yankson (2014) sobre os desafios da formalização e o trabalho de campo realizado nessa pesquisa.

Desta forma, chegou-se à definição de categorias analíticas que buscavam evidenciar o 1) acesso das cooperativas ao direito mineral; 2) a estrutura e articulação dos órgãos ambiental e mineral; 3) a gestão ambiental realizada pelas cooperativas; 4) o acesso às políticas públicas; 5) as linhas de financiamento de fomento ao setor; por fim, 6) a questões relacionadas a gestão e informação e as condições de trabalho na MPE.

A pesquisa seguiu os preceitos éticos que envolvem seres humanos, em conformidade com que prevê a Resolução do Conselho Nacional de Saúde, 466/2012 obtendo aprovação do Comitê de em Ética em Pesquisa da Universidade Federal de Lavras (parecer nº 799.985).

\section{ALGUMAS DESCOBERTAS DA PESQUISA}

Descrevemos nessa seção as circunstâncias em que as cooperativas foram constituídas para, em seguida, apresentar as considerações sobre o ordenamento normativo e os desafios da formalização e da operacionalização da atividade mineral. 


\subsection{A trajetória de formação das cooperativas}

\subsubsection{O Caso da Cooperativa Uniquartz}

O munícipio de Corinto está localizado na região Central de Minas Gerais, é um dos maiores produtores mundiais de quartzo. Estima-se que $25 \%$ da população do município esteja envolvida com a atividade mineral. A produção do mineral contribui com aproximadamente $40 \%$ do Produto Interno Bruto (PIB) do município. (SEBRAE, 2014). Porém, trata-se de uma atividade informal ainda realizada em sua maioria de forma clandestina, como lembrou o representante do poder público local.

No ano de 2005, mediante pressão dos órgãos fiscalizadores do Governo Federal, e frente a realidade da informalidade, um grupo inicialmente de 70 garimpeiros, iniciou o processo de constituição da cooperativa. $\mathrm{O}$ receio era que, se os garimpos fossem fechados, seriam apreendidos os maquinários e as mercadorias extraídas, bem como multados os proprietários das terras onde ocorriam os garimpos irregulares. Os relatos dos dirigentes entrevistados nos indicam que a forma organizacional cooperativa favorecia a obtenção da permissão da lavra garimpeira e assim poderiam garimpar de forma legalizada, bem como sanar problemas derivados da informalidade.

Os argumentos de um dos dirigentes corroboram este posicionamento: "a gente pensava que ao constituir a cooperativa todos os problemas iam resolver, porque existe um problema sério lá fora, o Governo Federal estava se preparando para ter uma fiscalização mais rigorosa que até então não existia" (Dirigente 01 da Cooperativa Uniquartz, nov./2014). A pressão do ambiente institucional forçou a modificação de ações por parte dos garimpeiros. A indução da forma organizacional está, assim, diretamente conectada com esse movimento provocado pelas forças coercitivas vindas da base jurídica.

Como lembrou Costa (2007, p. 271), "vítimas da coerção estatal unem-se para antecipar a fiscalização e se organizam em função dela", como no caso da constituição desta cooperativa. No processo de constituição da cooperativa, desde as primeiras reuniões, em 2005 até a concretização da constituição da cooperativa, em dezembro de 2007, vários desafios foram enfrentados pelos garimpeiros. Nos relatos dos dirigentes entrevistados percebe-se a ausência de conhecimento do processo de constituição de uma cooperativa em termos documentais, recursos financeiros para iniciar as atividades e a dificuldade de mobilização dos garimpeiros em prol da constituição da cooperativa.

Assim, em 2007, no dia 21 de dezembro, um grupo remanescente de 24 associados formou a cooperativa. Até 2015, a cooperativa congregava cerca de 100 associados, entre eles garimpeiros, mineradores, lapidários e transportadores de quartzo. No ano seguinte à formalização da cooperativa, a região Central de Minas recebeu grande fiscalização do Governo Federal. Nesse processo de fiscalização a cooperativa assumiu perante o Ministério Público uma ação de conscientização dos garimpeiros que garimpavam irregularmente, causando impactos ambientais. Além do trabalho social e econômico a cooperativa teria grandes desafios na consolidação de práticas de gestão ambiental.

Diante do exposto, observa-se que a cooperativa em movimento de reação ante ao processo de fiscalização se organizou para antecipar-se ao processo regulatório e continuar garimpando, o que corrobora com as problematizações apresentadas por Zucker (1987) \& Bowring (2000), ao elucidarem a influência do ambiente institucional no comportamento dos atores sociais, que reagem de forma adaptativa às pressões do contexto externo.

\subsubsection{O Caso da Cooperativa Microminas}

Situado às margens da Rodovia MG 050 na altura do quilômetro 212 no Oeste de Minas Gerais, no município de Córrego Fundo que possui sua economia local baseada na mineração e industrialização 
da cal. Porém, grande parte da atividade era realizada de forma clandestina. Diante desta situação, no ano de 2005 a Fundação Estadual do Meio Ambiente (FEAM), juntamente à Polícia de Meio Ambiente do Estado, o DNPM, o Instituto Brasileiro do Meio Ambiente e dos Recursos Naturais Renováveis (IBAMA), a Promotoria de Justiça de Arcos e a Coordenadoria das Promotorias de Defesa do Meio Ambiente do Alto Rio São Francisco realizaram uma ação de combate à mineração ilegal de calcário denominada 'Operação Calcário - Fase 2' nos municípios da região. Nessa operação, 15 lavras clandestinas realizadas nos municípios foram embargadas, elas não possuíam licença ambiental e nem registro do DNPM para operarem. (MINAS GERAIS, 2005).

Entre as irregularidades levantadas pela FEAM no processo de fiscalização das lavras ilegais estavam o "uso inadequado dos explosivos. Com a ausência de condutas ordenadas de plano de fogo, o desmonte da rocha torna-se sinônimo de risco de acidentes, o que resulta em ruídos elevados, vibrações no terreno e lançamento de pedras." (MINAS GERAIS, 2005). Esse processo causava acidentes de trabalho e vítimas fatais no processo de extração. Além dessa questão, a mineração era realizada de forma predatória, com baixo aporte de recursos tecnológicos e de maquinário.

Os mineradores que atuavam ilegalmente e individualmente foram notificados para assinarem um Termo de Ajustamento de Conduta (TAC) junto ao Ministério Público, com interveniência da FEAM, IBAMA e DNPM. Nesse termo estavam previstos os prazos para regularização ambiental, recuperação das áreas degradadas e a recomendação da constituição de uma cooperativa para poder regularizar a situação das pedreiras de calcário que eram exploradas ilegalmente.

Assim, em 2005, nascia a Cooperativa Microminas, congregando 30 pessoas. Segundo um dos dirigentes, quando houve a recomendação para formalizarem a cooperativa "a gente não tinha nem ideia do que ia ser, mas a gente entendeu que se a gente não se organizasse a gente não ia conseguir, o licenciamento ambiental é uma parte muito pesada para quem mexe na área de mineração." (Dirigente 01 da Cooperativa Microminas, DEZ/2014).

Em seu relato aparecem alguns desafios enfrentados pelos pequenos mineradores, um deles seria se organizarem de forma coletiva, pois, antes da formalização da cooperativa cada um trabalhava de forma individual nas suas pedreiras. Outro desafio seria a compreensão sobre o trabalho de uma cooperativa, o que endossa as questões discutidas quanto ao aspecto cultural do ambiente institucional da MPE, marcado pelo conflito entre a realidade garimpeira, individualista (GUANÃES, 2001; GUIMARÃES, 1982), e a cultura cooperativista, coletiva. (RIOS, 1987; SCHNEIDER, 1999; 2012). Por fim, a dificuldade em obter o licenciamento ambiental.

Diante do exposto, depreende-se que a cooperativa foi constituída para atender as exigências legais do TAC. Portanto, houve imposição da forma organizacional aos pequenos mineradores pelo ambiente institucional. Não houve apontamentos no trabalho de campo que ao longo do seu processo, a formação da cooperativa figurou como um movimento de cooperação para o processo produtivo, e sim para uma convergência de interesses comuns, legalizar a atividade para que todos pudessem continuar exercendo suas atividades. Dito de outra forma, antes do processo de fiscalização estatal, segundo relatos dos dirigentes, não houve nenhum movimento coletivo no sentido de constituir uma sociedade cooperativa para organização da atividade mineral no município.

Ou seja, reforça mais uma vez, o argumento de Bowring (2000), que aponta que organizações criam formas para se adaptar as pressões do ambiente institucional para continuar desenvolvendo suas atividades. Até porque, era a atividade econômica daqueles trabalhadores. 


\subsection{O ordenamento normativo e os desafios da formalização}

\subsubsection{Acesso ao direito mineral}

Superados os desafios iniciais da formalização da entidade enquanto pessoa jurídica como apontado nos casos das cooperativas, a segunda etapa passa pela obtenção do direito mineral. As cooperativas pesquisadas neste estudo, atuam sob dois regimes, a Cooperativa Uniquartz trabalha sob o regime de permissão de lavra garimpeira e a Cooperativa Microminas, no de licenciamento. (BRASIL, 1967). A permissão do DNPM depende previamente de licenciamento ambiental concedido pelo órgão competente.

Dentre os entraves citados pelas cooperativas para obtenção dos registros junto aos órgãos do Poder Público para poder minerar constam a demasiada exigência documental exigida pelo arcabouço legal e o tempo de resposta dos processos dos órgãos competentes, bem como sensibilização quanto à aplicação e atendimento da legislação inerente às cooperativas minerais. Outro ponto desafiante para ambas cooperativas investigadas foi e continua sendo o acesso formal à área mineralizada necessário para compor o processo de documentação para obtenção do direito mineral e os custos inerentes à obtenção do direito mineral.

Soma-se a tais desafios a contradição existente entre o Regime de Permissão de Lavra Garimpeira e o de Licenciamento voltado para o garimpeiro e os pequenos mineradores e a legislação mineral voltada para o grande empreendimento. Segundo o representante do DNPM/MG, apesar dos regimes de licenciamento e permissão de lavra garimpeira terem emergido no ordenamento jurídico mineral para agilizar e contemplar alguns setores, "todo o regime de autorização e concessão, nosso principal regime no DNPM, no direito minerário é para grandes empreendimentos." (Representante do DNPM/MG, dez/2014).

Como se observa, há uma clara divisão legal entre a MPE e a grande mineração. Entretanto, mesmo o ordenamento jurídico brasileiro estabelecendo esta divisão legal, os requisitos ou estratificação para as diferentes escalas de mineração para obtenção do direito mineral, deve ser atendido tanto pelos pequenos mineradores quanto pelos grandes mineradores. De certa forma, esta contradição contribui para manutenção da atividade da MPE na ilegalidade e, ao mesmo tempo, favorece os grandes empreendimentos pelas razões já evidenciadas ao longo deste estudo. Assim, os desafios apontados contribuem para reforçar os argumentos discutidos por Echavarria (2014), Fold, Jonsson \& Yankson (2014) e Ledwaba, (2017).

Apesar dos desafios, é notório que a formalização traz mais segurança jurídica aos garimpeiros e pequenos mineradores, ao mesmo tempo, contribui para diminuir os riscos da fiscalização do Estado, envolvendo paralização das atividades, apreensão de maquinário, responsabilização por crime ambiental, supressão do direito de exploração mineral, entre outros. Ademais, ao obterem o direito mineral traz mais segurança ao Estado pelo fato dos empreendimentos da MPE estarem operando sob a égide das normas ambientais e minerais. Todavia, os órgãos responsáveis por essas áreas enfrentam problemas que dificultam a obtenção do direito mineral pelas cooperativas minerais.

\subsubsection{Estrutura e Articulação dos Órgãos Ambiental e Mineral}

Em contraposição aos desafios apresentados na obtenção do direito mineral, segundo os dirigentes das cooperativas estudadas, tanto os órgãos ambientais quanto o mineral alegam reduzido orçamento, quadro funcional e acúmulo de trabalho o que inviabiliza uma resposta dos processos em tempo hábil. Segundo o representante do DNPM, o órgão não consegue acompanhar os processos de 
fiscalização e muito menos de apoio ao desenvolvimento da MPE em função dos problemas citados pelos dirigentes. $\mathrm{O}$ órgão mineral é um dos principais atores envolvidos no processo de licenciamento mineral. Para o entrevistado do DNPM/MG, devido às questões orçamentárias e de quadro técnico limitado, este órgão não vem conseguindo nem exercer a sua função básica, que é a análise dos processos. Essa é uma das questões que contribui para que muitas atividades da MPE permaneçam na ilegalidade, como a dos garimpos de quartzo em Corinto.

Neste sentido, caberia uma maior articulação dos órgãos de licenciamento ambiental e mineral, atuando de forma mais sinérgica e integrada para reduzir o tempo e o custo de obtenção do direito mineral. Para Milanez \& Puppin (2009), esta desarticulação é prejudicial para o Estado, em função dos recursos desperdiçados com processos incorretos, bem como para as empresas, que acabam postergando para começar a operar suas atividades e, também, pelo custo com atividades desnecessárias. Ademais, segundo os autores, "essa realidade termina, ainda, por desestimular a formalização das atividades, uma vez que pequenos empresários acabam preferindo atuar na informalidade e correr o (baixo) risco de multas a ter que passar por um processo tão lento e custoso." (MILANEZ; PUPPIN, 2009, p. 541).

Com o intuito de aumentar o orçamento, o poder de atuação e maior agilidade na análise dos processos junto ao órgão mineral, o Governo Federal transformou o DNPM numa agência reguladora da mineração, a Agência Nacional de Mineração (ANM), conforme Lei n ${ }^{\circ} 13.575$, de 26 de dezembro de 2017. (BRASIL, 2017). A nova agência tem como atribuições a promoção, regulação e a fiscalização dos recursos minerais.

Entretanto, argumenta-se que os principais atores que estiveram presentes na discussão deste novo ordenamento jurídico, iniciado em 2013 foram os grandes empreendimentos, indicando, assim, que as questões da MPE foram relegadas a segundo plano. (BUSTAMANTE et al., 2013). Em consonância com expectativa de mudança legal, para o representante do MME entrevistado, está havendo uma mudança estrutural nos órgãos de fiscalização e registro da mineração e a tendência é intensificar a fiscalização, apertar o cerco para a atividade ilegal.

Claro que a intensificação das fiscalizações poderá reduzir algumas áreas operadas ilegalmente, entretanto, o combate a mineração ilegal não é tarefa trivial. Costa (2007) ressalta que, devido às questões de fiscalização por parte do Estado e pela natureza da atividade, os garimpeiros se organizam em uma estrutura provisória, sem muito investimento em capital fixo e de longo prazo, o que permite a mudança rápida para outra localidade e, portanto, mais difícil de ser combatida pelos agentes de fiscalização do Poder Público. Esse aspecto também dificulta o fomento à formalização e organização destes trabalhadores. Desta forma, indica a necessidade de acompanhar mais de perto a MPE pelos órgãos ambiental e mineral (MILANEZ; PUPPIN, 2009), ou seja, uma atuação muito mais propositiva com políticas públicas do que repressiva do Estado.

\subsubsection{Gestão Ambiental}

No processo de fiscalização das cooperativas por agentes do Estado, ambas foram consideradas predatórias em termos de exploração mineral, o que assevera ainda mais a degradação dos recursos ambientais. Uma das questões que pode contribuir para melhoria da gestão ambiental é a inserção de tecnologia, que na MPE no Brasil, assim como na África do Sul e em outros países da América do Sul é considerado baixo, variando de inserção de ferramentas rudimentares a uma mecanização em escala limitada. (BARRETO, 2001; MMSD, 2002; LEDWABA, 2017). Desta forma, contar com tecnologia adequada pode contribuir na melhoria das operações para que elas sejam mais organizadas, seguras e ambientalmente corretas. (LEDWABA, 2017). 
A forma de garimpar predominante na Cooperativa Uniquartz até ano de 2013 era realizada sem aporte tecnológico, com o uso de alguns equipamentos pelos garimpeiros como a picareta, a pá, a alavanca e marretas. A partir deste ano houve a inserção de um maquinário (retroescavadeira). Esse processo de mecanização da cooperativa altera o garimpo artesanal ou manual para o semimecanizado. (COSTA, 2007). No garimpo artesanal, situação inicial dessa cooperativa havia baixo aporte de capital investido, o processo de extração do quartzo era realizado predominantemente na superfície, caracterizando, assim, como uma atividade de faiscação e sem a adoção das técnicas de sondagem para identificar a localização das jazidas, sendo executada em muitas situações de forma individual ou em formas familiares.

No garimpo artesanal, a lavra do quartzo era considerada predatória, pois, somente aproveitavase o cristal do quartzo, o material mais nobre, ou seja, de valor para o mercado. Dessa forma, seus subprodutos eram descartados, não os aproveitando. Já o garimpo semimecanizado caracteriza-se pelas inserções de alguns maquinários, neste caso, a retroescavadeira, e alguns processos diferentes dos realizados no manual para agregar valor ao produto extraído. Como exemplo, cita-se a passagem do quartzo numa grande peneira para separar o quartzo da terra e logo em seguida a lavagem do mineral, para que ele possa ser enviado aos depósitos e aos lapidadores e em seguida ser comercializado.

Diante desta situação, em processo de fiscalização realizado no ano de 2008 como descrito na seção de trajetória de formação das cooperativas, as atividades de extração foram consideradas predatórias. Além das ações de conscientização dos garimpeiros que garimpavam irregularmente, causando impactos ambientais, a cooperativa Uniquartz teve que mudar sua forma de exploração dos recursos minerais, bem como recuperar as áreas degradadas.

Em situação similar, o caso da Cooperativa Microminas, indica que de 2005 a 2010 a forma de extração foi considerada predatória pelos órgãos estatais em função dos impactos ambientais causados pela exploração do calcário, como a retirada da vegetação nativa, a erosão, o assoreamento dos cursos d'água, bem como a destruição de grutas e cavernas, presentes nas regiões com formação calcária.

No processo de extração mineral da cooperativa Microminas cada um dos associados fazia sua própria extração na frente de trabalho, com seu próprio maquinário, mão de obra, além do mais, era responsável pela comercialização de sua produção. Desta forma, o foco da extração eram as pedras com maior facilidade de serem extraídas e com maior possibilidade de renda no mercado. Os rejeitos não eram reaproveitados para outros fins o que acabava ocasionando poluição. Além do mais, não havia preocupação com a recuperação das áreas degradadas no processo de exploração. Assim, depreende-se que à cooperativa cabia apenas a gestão do direito mineral, ou seja, ela deveria buscar formalizar as áreas junto aos órgãos ambiental e mineral.

Em função desse contexto, houve na região no ano de 2010, mais uma operação de combate a lavra predatória e do trabalho irregular. A partir desta fiscalização, a Cooperativa Microminas teve que mudar a forma de exploração dos recursos minerais onde eram distribuídas em cerca de 30 frentes de lavra para os associados, que eram os responsáveis pelo processo de extração e comercialização do mineral e concentrar suas operações num único local. A cooperativa também passou a ser responsável por todo o processo de extração e comercialização do mineral, bem como pela gestão dos impactos ambientais. Desta forma, percebe-se que a partir de uma imposição legal, a cooperativa num movimento adaptativo mudou a sua forma de organização e gestão do trabalho.

Segundo os dirigentes dessa cooperativa, a ação do poder público foi positiva e com a alteração da forma de exploração dos recursos minerais em detrimento do processo fiscalizatório possibilitou a redução nos custos na forma de minerar. Essa mudança no entendimento dos dirigentes da Microminas facilitou a gestão e controle dos recursos minerais, bem como proporcionou melhor aproveitamento do mineral e menor impacto ambiental, como aconteceu na Cooperativa Uniquartz. 


\subsubsection{Políticas Públicas}

A formalização da cooperativa, conforme explicita o Plano Nacional de Mineração 2030 (PNM, 2030), pode proporcionar aos trabalhadores da mineração o acesso a algum tipo de apoio oficial por meio de políticas públicas. (BRASIL, 2010). As duas cooperativas investigadas relataram não fazer parte de nenhum programa ou política pública de concessão de fomento, assim, como cerca de $90 \%$ das cooperativas que participaram de um estudo sobre o diagnóstico do ramo mineral elaborado pela Organização das Cooperativas Brasileiras (OCB), também não são contempladas com nenhuma política pública em âmbito federal, estadual ou municipal (SISTEMA OCB, 2016). Apesar de incentivar através do incentivo regulatório a constituição das organizações, o Estado parece se ausentar em relação a promoção de apoios específicos a MPE, ou seja, o Estado requer a constituição, mas não oferece meios (suporte, assessoria, treinamentos etc.) para o desenvolvimento do setor.

Sobre essa questão, Bitencourt \& Amodeo (2008) fazem uma crítica ao papel desempenhado pelo Estado em relação ao fomento do cooperativismo mineral. Para as autoras, se o "Estado deseja promover o desenvolvimento dos garimpeiros através de organizações cooperativas, não basta que apenas formalize a criação de entidades dessa natureza e esperar que tais alcancem os objetivos." (BITENCOURT; AMODEO, 2008, p. 14).

Desta forma, o papel do Estado se reduz a incentivar a formalização, sem considerar as implicações que o processo pode causar na vida dos trabalhadores e nas relações sociais existentes, pois, o "simples incentivo através da prioridade de lavra as cooperativas de garimpeiros através da Constituição Federal de 1988 pode não vir a resultar em benefícios reais para os garimpeiros." (BITENCOURT; AMODEO, 2008, p. 14).

Em função disso, no debate sobre a proposição do Novo Código Mineral, os representantes dos interesses das cooperativas minerais, a OCB se articulou juntamente com a Frente Parlamentar do Cooperativismo $\left(\right.$ FRENCOOP $^{5}$ ) para tentar inserir no Novo Código os interesses de seus representados.

Dos pleitos do sistema cooperativista, $80 \%$ das solicitações foram atendidas pelo então relator da matéria, Deputado Leonardo Quintão do PMDB/MG (OCB, 2014), que também era membro da Frencoop. Dentre os pleitos estavam: linhas de financiamento para o setor (nosso próximo tópico); adequação dos prazos para o desenvolvimento em relação ao investimento; fomento das cooperativas pelo Governo de forma organizada e articulada com o Sistema OCB; redução dos custos, como os tributários às cooperativas para facilitar a implementação das atividades e obrigatoriedade de registro das cooperativas minerais junto à OCB para conseguirem obter o direito mineral. (FERREIRA, 2014)

\subsubsection{Linhas de Financiamento}

Outro entrave apontado pelas cooperativas refere-se à dificuldade de acesso ao crédito junto às instituições financeiras, o que também foi identificado no estudo da OCB. O diagnóstico do ramo mineral identificou que 70\% das cooperativas não acessam nenhuma linha de financiamento (SISTEMA OCB, 2016). Desta forma, há uma exigência dos próprios cooperados aportarem capital na cooperativa. A difícil situação econômica de alguns cooperados pode tornar essa ação complexa.

Esse desafio está consubstanciado no PNM 2030, onde foi diagnosticado que "para as MPEs, o

\footnotetext{
${ }^{5}$ Contribuir para o aperfeiçoamento do marco regulatório de interesse do Sistema Cooperativista Brasileiro, a partir de uma atuação articulada e transparente. Essa é a missão da Frente Parlamentar do Cooperativismo (Frencoop), bancada formada por deputados e senadores que participam das discussões e deliberações legislativas referentes ao setor, tanto nas comissões temáticas, como nos plenários das duas Casas Legislativas (OCB, 2018).
} 
fomento e o crédito subsidiado são imprescindíveis" e sendo necessário "garantir disponibilidade maior e contínua de recursos." (BRASIL, 2010, p. 69). E, como ação para tentar garantir o cumprimento, o Ministério de Minas e Energia (MME) prevê "entendimentos interministeriais visando à criação de linha de financiamento para formalização e modernização técnica das MPEs, com o objetivo de ampliar a eficiência produtiva, e à promoção de treinamento gerencial." (BRASIL, 2010, p. 127).

Ademais, a imagem que o setor bancário tem em relação às organizações da MPE de ausência de cumprimento da legislação ambiental e mineral, acaba por influenciar no lançamento de linhas de crédito, como ponderou o Sistema OCB (2016).Soma-se a esse contexto, o fato de ser um negócio arriscado e incerto, o que leva as instituições financeiras a ter receio de oferecer crédito à esta atividade, e por isso, não aceitam o título minerário como garantia no empréstimo.

Além do mais, a falta de conhecimento quanto ao potencial de recursos minerais e da vida útil da jazida, bem como do valor econômico do depósito, da disponibilidade do mercado em demandar àquele produto, do fluxo de caixa da organização e de problemas de gestão relacionados a falta de habilidade gerencial, acabam por complicar o acesso ao crédito pelos empreendimentos da MPE (LEDWABA, 2017).Uma alternativa seria as cooperativas de crédito oferecem linhas de crédito para essas organizações, mas essa não é a realidade do setor.

\subsubsection{Gestão e Informação e condições de trabalho}

A gestão e informação nas cooperativas minerais é fundamental para que as organizações possam ser mais eficientes, para que elas conheçam as técnicas e os processos de pesquisa e extração dos recursos minerais. Com isso, podem realizar uma lavra menos ambiciosa e predatória, fatores agravantes que prejudicam o aproveitamento do bem mineral e do meio ambiente. (BARRETO, 2003).

Com o processo fiscalizatório e a obrigatoriedade de cumprir normas de exploração dos recursos minerais, os garimpeiros e os pequenos mineradores, que antes atuavam de forma clandestina, com a formalização em cooperativas foram obrigados a atender algumas exigências dos ordenamentos jurídicos, tanto no processo de extração do minério, quanto nas condições de trabalho para exploração dos recursos minerais. Como asseverou Siegel \& Veiga (2009), o reconhecimento legal da organização impõe deveres para que ela atue segundo os preceitos ambientais, trabalhistas e de respeito à condição humana.

Desta forma, acabou demandando das cooperativas investigadas, uma maior profissionalização das atividades, contratando, por exemplo, alguns profissionais internos ou externos, como consultor ambiental, jurídico, segurança do trabalho, entre outros. Situação mais bem vivenciada na Cooperativa Microminas, que possuí uma melhor capacidade financeira, do que a realidade da Cooperativa Uniquartz.

É neste contexto que contar com suporte institucional pode ajudar no desenvolvimento dos empreendimentos da MPE, principalmente aquelas organizações menos estruturadas (LEDWABA, 2017), como é o caso da Cooperativa Uniquartz. Assim, uma ação integrada dos governos nos níveis Federal, Estadual e Municipal, articulados com instituições de representação e fomento do cooperativismo, bem como, com sindicatos e outras organizações pode contribuir para atender as necessidades do setor e, em especial, das cooperativas minerais.

Como já apontado, a carência e o acesso à informação é um dos desafios da MPE. Por exemplo, no Diagnóstico do Ramo Mineral, as cooperativas identificaram necessidade de trabalhar melhor a questão da fidelização dos cooperados; gestão administrativo-financeira; qualificação dos empregados; formação de novas lideranças; gestão de processos e a necessidade de elaborar planejamentos estratégicos. Além do mais, apontaram a oportunidade de melhorar a competitividade da cooperativa frente a outras formas societais. (SISTEMA OCB, 2016). Em relação a este último desafio, treinamentos que contemplassem ou ajudassem na previsão da localização dos minerais, na geologia e qualidade 
do mineral, bem como nas técnicas de extração e processamento, poderiam contribuir para melhorar a competitividade destas organizações. (LEDWABA, 2017).

Ademais, uma atuação mais presente das entidades de representação e fomento ao cooperativismo poderia amenizar parte das necessidades apontadas pelas cooperativas investigadas neste estudo, que evidenciou uma fragilidade no atendimento da Unidade Estadual junto às cooperativas minerais. Todavia, observa-se uma tentativa de atuação e condução mais presente por parte da entidade nacional junto ao poder público, bem como uma presença em termos de orientação às unidades estaduais. Assim, caberia refletir sobre o papel da entidade de representação do cooperativismo em MG, de fomentador, de ser o agente propulsor e garantidor da qualidade e eficácia do sistema cooperativista no Estado como consta em sua missão institucional.

\section{CONSIDERAÇÕES FINAIS}

A proposta desse estudo foi discutir como o ambiente institucional da MPE contribui para efetivar a formação de cooperativas minerais. Para tanto, a partir do estudo de caso de duas cooperativas, a Uniquartz e a Microminas, ambas no Estado de Minas Gerais, buscou-se elucidar, diante do processo de constituição dessas organizações, os desafios enfrentados na formalização e operacionalização da atividade mineral.

A constituição das cooperativas analisadas neste estudo ilustra o processo de tentativa do Estado de legalizar a MPE, que fora realizada ao longo da história de forma individual e competitiva, e com pouco espaço para cooperação.

Ademais, trata-se de uma atividade de grande impacto ambiental e social. Neste sentido, a figura cooperativa emerge na MPE para realizar uma nova função social, a gestão do direito minerário e a gestão dos impactos ambientais decorrentes da extração mineral, o que é positivo para a sociedade e Estado. Do ponto de vista estatal, facilita-se o processo de fiscalização e responsabilização pelos danos ambientais, bem como a apropriação da riqueza gerada por essa atividade que lhe é de direito. Mas, cabe ressaltar que apenas formalizar a organização não é garantia para o alcance dessas funções conforme visto ao longo desse estudo.

Nos casos estudados, percebe-se movimentos distintos de constituição das cooperativas. Os garimpeiros que se organizaram na Uniquartz o fizeram no sentido de antecipar ao processo de fiscalização, enquanto os pequenos mineradores da Microminas, se organizaram a partir da imposição estatal. Em função da natureza de constituição e, posteriormente, das intervenções estatais relacionadas a fiscalização da atividade mineral, as cooperativas organizaram de formas diferentes os seus processos produtivos, o que interferiu na participação e envolvimento dos associados no processo produtivo e na dinâmica dos desafios enfrentados.

Com a análise dos casos foi possível visualizar que o processo de formalização é complexo em função dos diferentes desafios enfrentados pelas cooperativas desde a constituição à operacionalização da atividade mineral. Observou-se que apesar do ambiente institucional garantir regulamentações a este formato organizacional na MPE, não oferece meios para o desenvolvimento desse formato organizacional, como por outras políticas públicas de crédito, com legislação adequada aos empreendimentos, de assessoria e treinamento, tecnologia, suporte organizacional, entre outros. Como consequência, há comprometimento da gestão mineral e ambiental realizados por essas organizações.

Mas não só isso, constrange as possibilidades de desenvolvimento econômico e social dos trabalhadores, neste caso, associados das cooperativas. Em decorrência disso, os resultados dos processos de cooperação em volta da cooperativa poderão ser apropriados por aqueles grupos ou indivíduos como melhores posições sociais, culturais, econômicas e políticas. 
Essa seria uma das consequências daquilo que Freitas, Freitas e Macedo (2016) discutiram como processo de indução à formalização de cooperativas minerais por parte do Estado. Para os autores, a indução dessa forma organizacional, como principal modo de organizar socialmente os garimpeiros e os pequenos mineradores, bem como um meio de ampliar a regulação estatal e o acesso a políticas públicas pode resultar na constituição de organizações desconectadas das dinâmicas sociais locais, afetando, assim o desenvolvimento local.

Ou seja, a indução na perspectiva dos autores para despertar, bem como fortalecer iniciativas pré-existentes localmente requer "a adequação das instituições e das organizações a seus contextos sociopolíticos e culturais." (FREITAS, FREITAS, MACEDO, 2016, p. 113). Desta forma, a figura cooperativa emergiria como um espaço propício ao exercício da cooperação, nos aspectos relacionados à cooperação para o processo produtivo, a convergência de interesses comuns, bem como propiciaria a esses trabalhadores a possibilidade de reflexão para uma mudança sócio política.

Por fim, é importante ressaltar que as reflexões propostas caminham no sentido de uma tentativa de conhecimento deste universo dinâmico e não tem a pretensão de qualquer prescrição, apontamento de um caminho a ser trilhado, muito pelo contrário, convida-se os demais pesquisadores a se debruçarem sobre este tema. Com esse trabalho, espera-se ter trazido à tona alguns desafios enfrentados pelas cooperativas desse setor visto de forma marginal por distintos atores e, assim, servir de instrumento de informações para o Poder Público, as entidades de representação do cooperativismo e a sociedade.

\section{REFERÊNCIAS}

BARRETO, M. L. Mineração e desenvolvimento sustentável: desafios para o Brasil. Rio de Janeiro: CETEM: MCT, 2001. 215p.

. Formalização da mineração a pequena escala (MPE) na América Latina e Caribe. Estudo financiado pelo Programa Mineria Artesanal y em Pequeña Escala (MPE) do IDRC/CRDI/ MPRI/IIPM, julho de 2003.

BITENCOURT, M. A. Cooperativismo e atividade garimpeira: o caso da cooperativa garimpeira do vale do rio da bagagem Ltda. 2009. 158 p. Dissertação (Mestrado em Extensão Rural) Universidade Federal de Viçosa, Viçosa, MG, 2009.

BITENCOURT, M. A. et al. Cooperativismo nos garimpos: potencialidades e limitações a partir de um estudo de caso. Organizações Rurais e Agroindustriais, Lavras, v. 12, n. 3, p. 399-410, 2010.

BRASIL. Decreto-Lei no 227, de 28 de fevereiro de 1967. Brasília, 1967. Disponível em: <http:// www.planalto.gov.br/ccivil_03/decreto-lei/del0 227.htm>. Acesso em: 15 dez. 2017.

. Lei no 7.805, de 18 de julho de 1989. Brasília, 1989. Disponível em: <http://www. planalto.gov.br/ccivil_03/Leis/L7805.htm>. Acesso em: 15 dez. 2017.

. Departamento Nacional de Produção Mineral. Cooperativismo mineral no Brasil: o caminho das pedras, passo a passo. Brasília, 2008. 
. Lei $\mathrm{n}^{\circ} 11.685$, de 2 de junho de 2008. Institui o Estatuto do Garimpeiro e dá outras providências. Diário Oficial da União: seção 1, Brasília, DF, ano CXLV, n. 104, 3 jun.2008.

. Lei n ${ }^{\circ} 13.575$, de 26 de dezembro de 2017. Diário Oficial da União: seção 1, Brasília, DF, edição 247, p.1-4, 27 dez.2017.

. Decreto $n^{\circ} 9.406$ de 12 de junho de 2018. Diário Oficial da União, Brasília, DF, p.1, 13 jun.2018.

. Ministério de Minas e Energia. Plano Nacional de Mineração 2030 (PNM - 2030)

Brasília: MME, 2010, 178 p.

Bustamante, L. A. da C. et al. Análise do Projeto de Lei de Marco Regulatório da

Mineração do Brasil. Brasília: Núcleo de Estudos e Pesquisas: CONLEG: Senado, 2013.

BOWRING, M. De/constructing theory - a look at the institutional theory that positivism built.

Journal of Management Inquiry, v. 9, n. 3, sept. 2000.

CHAKRAVORTY, S. L. Artisanal and Small-scale Mining in India. Inglaterra, n.78, out. 2001.

COSTA, L. R. Os garimpos clandestinos de ouro em minas gerais e no Brasil: tradição e mudança.

História \& Perspectivas, Uberlândia, v. 36, n. 37, p. 247-279, jan./dez. 2007.

ECHAVARRIA, C. What is legal: formalising artisanal and small-scale mining in Colombia. IIED, London and ARM, Colombia, 2014.

ELLA - EVIDENCE AND LESSONS FRON LATIN AMERICAN. Small-Scale and informal mining: a big problem for Latin American States. Dec. 2012.

FERREIRA, V. Cooperativas minerais apostam no novo marco regulatório. Informe OCB Publieditorial. 06 nov. 2014. Disponível em: < http://revistagloborural.globo.com/Informe-OCB/ noticia/2014/11/cooperativas-minerais-apostam-no-novo-marco-regulatorio.html >. Acesso em: 10 dez. 2017.

FREITAS, A. F.; FREITAS, A. F.; MACEDO, A. S. Cooperativismo mineral: da indução de uma forma organizacional aos desafios de uma organização sustentável. Revista Brasileira de Gestão e Desenvolvimento Regional, Taubaté, SP, v. 12, n. 1, p. 107-131, jan./abr, 2016.

FOLD, N.; JONSSON, J. B.; YANKSON, P. Buying into formalization? State institutions and interlocked markets in African small-scale gold mining. Futures, v. 62, part A, p. 128-139, 2014.

FORTE, J. F. Cooperativa de pequenos mineradores: a experiência nos garimpos de pegmatitos do Nordeste. Dissertação (Mestrado em Geociências) - Universidade Estadual de Campinas, São Paulo, 1994. 150 p. 
GIL, A. C. Métodos e técnicas de pesquisa social. 5. ed. São Paulo: Atlas, 2007.

GODOY, A. S. Introdução à pesquisa qualitativa e suas possibilidades. Revista de Administração de Empresas, São Paulo, v. 35, n. 2, p. 57-63, mar./abr. 1995.

GUANÃES, S. A. Nas trilhas dos garimpeiros de serra: garimpo e turismo em áreas naturais na Chapada Diamantina-Ba. Dissertação (Mestrado em Antropologia) - Programa de Pós-Graduação em Antropologia da Unicamp: Campinas, SP, 2001.

GUIMARÃES, B. O garimpeiro. Rio de Janeiro: Guarnier, 1982. 247p.

HENTSCHEL, T. J.; HRUSCHKA, F.; PRIESTER, M. Global Report on Artisanal \& SmallScale Mining, London, n.70, jan. 2002.

IIED - International Institute for Environment and Development e WBCSD - World Business Council for Sustainable Development. Minería, Minerales y Desarrollo Sustentable: el informe del Proyecto MMSD. Reino Unido, Estados Unidos, 2002.

LEDWABA, P.F. The status of artisanal and small-scale mining sector in South Africa: tracking progress. J. S. Afr. Inst. Min. Metall., Johannesburg, v. 117, n. 1, p. 33-40, jan.2017.

LIMA, M. H. R. et al. Garimpo e inclusão social no Brasil: dois estudos de caso. In: III SEMINÁRIO INTERNACIONAL SOCIEDADE INCLUSIVA - Ações Inclusivas de Sucesso, 2004, Belo Horizonte. Anais [...] Belo Horizonte: PUC MINAS,2004, p. 15.

MACEDO, A. S. et al. Nem Tudo que Reluz é Ouro. Os Desafios de Cooperativas Minerais em Minas Gerais. Desenvolvimento em Questão, Ijuí, RS, v. 14, n. 36, 2016.

MEYER, J. W.; ROWAN, B. Organizaciones institucionalizadas: La estructura formal como mito y ceremonia. In: POWELL, W. W.; DIMAGGIO, P. J. (orgs.) El nuevo institucionalismo en el análisis organizacional. Tradução Roberto Ramón Reyes Mazzoni. México: Fondo de Cultura Económica, 1999.

MILANEZ, B.; PUPPIM, J. A. Ambiente, pessoas e labor: APLs além do desenvolvimento econômico na mineração de opalas em Pedro II, no Piauí. Cadernos EBAPE. BR, Rio de Janeiro, n. 4, p. 527-546, 2009.

MINAS Gerais: Feam embarga áreas clandestinas de extração de calcário. 2005. Disponível em: <http://www.paginarural.com.br/noticia/ 26094/minas-gerais-feam-embarga-areas-clandestinasde-extracao-de-calcario>. Acesso em: 25 mar. 2016.

MINAS GERAIS. Lei ${ }^{\circ}$ 15.075, de 05 de abril de 2004. Dispõe sobre a política estadual de apoio ao cooperativismo. Belo Horizonte, 2004. Disponível em: <http://www.fazenda.mg.gov.br/ empresas/legislacao_tributaria/leis/115075_2004.htm>. Acesso em: 15 dez. 2017. 
MMSD. Minería, Minerales y Desarrollo Sustentable en América Del Sur. Bolívia: Graphis Ltda, Bolivia, 2002.

ORGANIZAÇÃO DAS COOPERATIVAS BRASILEIRAS. OCB legislativo. Disponível em: <http://www.somoscooperativismo.coop.br/legislativo>. Acesso em: 02 jan. 2018.

Anuário do Cooperativismo Brasileiro. Brasília, DF, 2019.

RIOS, G. S. L. O que é cooperativismo. São Paulo: Brasiliense, 1987.

SALOMÃO, E. P. O ofício e a condição de garimpar. In: ROCHA, G. A. Em busca do ouro: garimpos e garimpeiros no Brasil. Rio de Janeiro: Marco Zero, 1984. p. 11-33.

SERVIÇO BRASILEIRO DE APOIO ÀS MICRO E PEQUENAS EMPRESAS. Territórios da cidadania: riquezas de um novo Brasil. Brasília, DF: Sebrae, 2014.

SCHNEIDER, J. O. Democracia, participação e autonomia cooperativa. 2.ed. São Leopoldo: Unisinos, 1999.

SCHNEIDER, J. O. A doutrina do cooperativismo: análise do alcance, do sentido e da atualidade dos seus valores, princípios e normas nos tempos atuais. Cadernos de Gestão Social, Bahia, v.3, n.2, p. 251-273, jul./dez. 2012.

SIEGEL, S.; VEIGA, M. M. Artisanal and small-scale mining as an extralegal economy: De Soto and the redefinition of “formalization”. Resources Policy, v. 34, n. 1-2, p. 51-56, mar. 2009.

SISTEMA OCB. Diagnóstico do ramo mineral: desafios para o setor. Sistema OCB - Gerência técnica e econômica. Brasília, 2016.

THE WORLD BANK. Artisanal and Small-Scale Mining. Nov. 2013. Disponível em: <http:// www.worldbank.org/en/topic/extractiveindustries/brief/artisanal-and-small-scale-mining > . Acesso em: 18 maio 2017.

VERGARA, S. C. Métodos de pesquisa em administração. 2. ed. São Paulo: Atlas, 2006.

ZUCKER, L. G. Institutional theory of organization. Annual Review of Sociology, v. 13, p. 443-464, 1987. 